Journal of Correctional Health Care 2020, Vol. 26(3) 240-248

\title{
Family Therapy in Corrections: Implications for Reentry Into the Community
} DOI: $10.1177 / 1078345820938350$ journals.sagepub.com/home/jcx

@SAGE

\author{
Micaela Garofalo, PhD'
}

\begin{abstract}
Prison life is often characterized by drug use, racial intolerance, and violence. This culture of criminality is juxtaposed to treatment efforts that address the criminogenic needs and risks that are associated with inmate institutional rule violations and reoffending in the community, thereby creating seemingly insurmountable challenges for treating clinicians. Rather than fighting a losing battle between treating staff and inmate peers, a more effective strategy may be to utilize family members as resources and allies in the process of change for incarcerated individuals. Challenges and solutions to family therapy prison program implementation are discussed.
\end{abstract}

\section{Keywords}

family therapy, reentry, recidivism, prison programs

The revolving-door analogy is often used to depict an ever-growing population of incarcerated offenders releasing from jails and prisons only to commit additional crimes or to violate the conditions of their probation and parole and to routinely find themselves reincarcerated in correctional institutions throughout the United States. In response to this disappointing trend in American corrections and in an effort to reduce the number of returnees, correctional administrators have turned their attention to programming that addresses inmate deficits.

In the last decade or so, as correctional systems, both state and federal, have had to address the problem of the revolving door with increasing dollar amounts, rehabilitative efforts that recognize the impact of community and family on offenders' ability to live crime-free lives have resurfaced. Accordingly, there is a renewed focus on preparing prisoners to reenter society with improvements in daily living skills. This has prompted greater interest in understanding the causes of rearrests and multiple incarcerations.

Researchers have found that in addition to a lack of education with many inmates not completing high school, vocational and employment skills, substance abuse and limited mental health treatment, and interpersonal problems play key roles in the formerly incarcerated returning to prison. Recidivism rates are highly correlated with antisocial risk factors (personality, behavior, peers, thinking) as

\footnotetext{
' Nevada Department of Corrections, Indian Springs, NV, USA 
well as criminogenic risk factors such as substance abuse, leisure activities, employment, psychopathology, low socioeconomic status, and family/couple stressors (Andrews et al., 2006). Mental health problems are often compounded by inefficient or inconsistent treatment resulting in negative consequences. Therefore, there is a need to address the criminogenic risk factors that result in too many offenders returning to prison.

Prison life is often characterized by drug use, racial intolerance, and violence. This culture of criminality is juxtaposed to treatment efforts that address the criminogenic needs and risks that are associated with inmate institutional rule violations and reoffending in the community, creating seemingly insurmountable challenges for treating clinicians. Rather than fighting a losing battle between treating staff and inmate peers, a more effective strategy may be to utilize family members as resources and allies in the process of change for incarcerated individuals.

As inmates are released into their communities, they often return to live with their immediate or extended families, significant others, and their children. Therapeutic interventions are needed to help improve the ability of incarcerated families to cope with the realities of transitioning from prison life to home life. A large number of offenders return to prison because they are illprepared to face difficult challenges that exist within families, including family conflict, psychopathology, substance abuse, and antisocial behaviors (Gendreau et al., 2004). Therapeutic interventions for couples and families of incarcerated individuals address an existing gap in prisoner reentry.

\section{A Brief History of Prison Programs}

The late 1960s and early 1970s in American corrections was a time of openness and interest in programming. It was a time in which the rehabilitation of offenders was viewed as necessary and important for American society. Professional staff initiated numerous programs in that period, including family therapy. While empirical evidence was still in its infancy during that time, what was noted was fewer disciplinary infractions from program participants.

By 1974, Martinson's "Nothing Works" article gave policy makers the impetus to defund programming and move into a "get tough on crime" approach to corrections (Gendreau et al., 2004). Although Martinson himself attempted to retract his initial evaluation of the ineffectiveness of programs, the world of corrections had left rehabilitation behind and entered into an era of retribution and intolerance toward criminal offenders. This era, characterized by the War on Drugs, mandatory minimum sentences, the Three Strikes Law in California, and prosecuting juveniles as adults, led to a dramatic rise in the number of people incarcerated in both federal and state prisons. Particularly affected by these policies were communities of color, who were arrested and sentenced at higher rates than their White counterparts (Andrews \& Bonta, 2010). The rates of mass incarceration have only increased since that time, overburdening government budgets with new prison construction and the need for more custody staff to supervise the growing number of inmates (Petersilia, 2003).

In the 1990s, it became clear that inmates who were simply warehoused in prison lacked the skills to improve their lives when they were released into their communities. Added to the failed tougher sentencing laws and prison crowding was an increase in reincarceration rates. A renewed interest in prison programming resulted, with recidivism rates used as the primary indicator of a successful program.

The most notable improvement that occurred in corrections was criminal justice researchers' ability to evaluate effective programming in correctional institutions. In other words, the measurement of effective versus ineffective programming became more sophisticated. Today, this is referred to as evidence-based practice (EBP), meaning that at least one study found the method to be promising. 


\section{Ineffective Programming}

Albert Ellis described most therapies as helping people feel better, not helping people get better. Researchers conducting evaluation studies found this to be true for a number of established programs both in prison and in the community. Among these programs is Scared Straight, which was not effective at deterring crime by exposing adolescents to maximum security prisons and prisoners (Andrews \& Bonta, 2010).

Another example of ineffective programming is boot camps. Boot camps were designed to reduce delinquency through military-style discipline. Studies failed to report any appreciable changes in adolescents who completed these programs (Andrews \& Bonta, 2010).

A third example is the Drug Abuse Resistance Education (D.A.R.E.)program that used police officers to educate children in schools about the dangers of illegal drugs. This had the opposite effect; children who participated in D.A.R.E. were more likely to experiment with illegal drugs than those who did not. Many of these programs still exist today as they have either been modified to adhere more closely to EBP or in some cases, sound research has simply not resulted in policy changes.

\section{Effective Programming}

On the other hand, what has been found to be effective with criminal justice populations is cognitive-behavioral treatment models. These address errors in thinking that sustain offenders' criminality by introducing more rational thinking, which in turn translates into prosocial behavioral changes. Contingency management programs, such as token economies, have also been found to impact positively on behavior (Lipsey et al., 2007). A third example of effective programming is the modified therapeutic community, which reduces relapses to drug use.

\section{What Works in Corrections}

\section{The Risk-Need-Responsivity (RNR) Principle}

Since the return of correctional programming in the 1990 s, researchers have focused their attention on the impact that prison programs have on reincarceration rates. Through numerous studies from the last two decades, a model known as the RNR principle has emerged that outlines what works in correctional programming to reduce criminal reoffending (Andrews \& Bonta, 2010).

RNR consists of the risk principle, which determines who should receive services-that is, moderate- and high-risk offenders. Targeting low-risk offenders does not seem to result in significant change in criminal attitudes or behaviors. The Need Principle governs the needs of inmates - criminogenic or dynamic risk factors - that should be addressed by the interventions. These criminogenic needs or dynamic risk factors that impact on recidivism include antisocial attitudes, antisocial personality, antisocial peers, vocational and educational accomplishments, family conflict, substance abuse, and leisure activities (Andrews \& Bonta, 2010). It is noteworthy that the fifth criminogenic need in this list is family conflict, which is addressed by family therapy.

The third component of RNR is the Responsivity Principle. This determines how treatment is delivered, namely through a cognitive social learning lens that matches treatment to the offender's individual characteristics. It is based on Bandura's self-efficacy theory and assumes that criminality is learned in the social environment. Thus, what has been learned can also be unlearned in the context of a prosocial environment (Andrews \& Bonta, 2010). 


\title{
Family Therapy \\ Youthful Offenders
}

Most of the research on family therapy in corrections has been conducted with youthful offenders and in the juvenile justice system. As a result, there are numerous family interventions that have been evaluated and found to meet the criteria of best practice. For instance, functional family therapy (FFT) is widely used to reduce juvenile delinquency and aggressive behavior by addressing faulty cognitions, negative emotions, and interpersonal relationship problems. FFT is a fairly brief intervention that is completed within 3 months (Celinska, 2015).

Another example of family programming that has shown promise in the community is multidimensional family therapy, which addresses substance abuse and criminality with a goal to prevent outof-home placement (Simons et al., 2017). Multisystemic therapy (MST) focuses on empowering caregivers to solve problems. For MST, families are seen as the solution (Henggeler \& Schaeffer, 2016). Brief strategic family therapy is a brief therapy, 8 to 24 sessions, that is problem focused (Szapocznik \& Williams, 2000). Lastly, Family Integrated Transitions is a reentry intervention that begins 2 to 3 months prior to release from juvenile justice facilities and continues in the community (Underwood et al., 2006).

\section{Female Offenders}

The literature on female offenders points to a need for gender-responsive interventions that address trauma-related problems. Two thirds of female offenders in state and federal facilities have at least one minor child from whom they are physically separated during the period of incarceration. The mental health impact of incarceration on both the mother and her dependent child, who is placed in foster care or living with other relatives, often presents with similarities to post-traumatic stress disorder and trauma. Incarcerated women often report histories of violent interpersonal relationships and associated substance abuse problems. Therefore, correctional programs that address the needs of the female offender population are generally trauma responsive. The Substance Abuse and Mental Health Services Administration (SAMHSA, 2014) outlines six main principles by which traumainformed approaches should focus:

\author{
Safety \\ Trustworthiness and Transparency \\ Peer support \\ Collaboration and Mutuality \\ Empowerment, Voice and Choice \\ Cultural, Historical, and Gender issues.
}

Trauma-informed family therapy is one such approach. It recognizes and responds to the impact of trauma on the lives of women (Underwood et al., 2006). Another trauma-related intervention is emotion-focused family therapy, which focuses on couples, relationship conflict, attachment issues, depressive disorders, and trauma. The importance of relationships in women's lives is noted both in prison and the community. For females, enhanced reentry outcomes are associated with self-reports of positive interpersonal relationships (Dowden \& Andrews, 2000).

\section{Adult Offenders}

As most of the literature on family therapy is focused on young offenders, there is a limited amount of empirical data regarding the effectiveness of family-focused interventions with adult criminal populations. However, in addition to interventions that are trauma-focused, some community-based 
interventions have been found to have promising results and are worthy of consideration for use in prison programming.

Cognitive-behavioral family therapy (CBFT), which utilizes cognitive-behavioral therapy techniques for work with families, is an evidence-based therapy that may be effective with criminal justice populations. CBFT significantly reduces internalizing disorders, such as depression and anxiety, and externalizing behaviors, such as aggression and substance abuse, and improves family cohesion (Hofmann et al., 2012; Kolko et al., 2014).

Another evidence-based therapy that has been found to be beneficial is systemic couple therapy. This intervention helps couples gain a greater understanding of one another and consequently learn more empathic attitudes toward their partners. Systemic couple therapy has also been linked to significant improvements in psychopathology (Carr, 2014).

Lastly, structural family therapy has been successfully applied with economically disadvantaged families, which make up the majority of the criminal justice population. This strength-based approach focuses on the context and structure of how families are organized. In structural family therapy, mental illness is viewed as a symptom of family dysfunction (Minuchin, 1974).

\section{Benefits of Family Therapy}

\section{Reductions in Recidivism}

The purpose of developing couple and family therapy programs in correctional institutions is to improve outcomes associated with the inmate population's criminal reoffending in the community as well as rule-violating behaviors in the institutions. Thus, therapeutic goals should focus on reducing family conflict (a dynamic risk factor linked to recidivism), identifying and managing emotional disorders, and ameliorating behavioral problems. This can be achieved through systemic and cognitive behavioral interventions that account for the effects of family and peer influences on criminal behavior.

The scientific literature supports the correlation between strong family bonds and low criminal reoffending (Barretti \& Beitin, 2010; Datchi \& Sexton, 2013; Underwood et al., 2006; Vera Institute of Justice, 2011). Incarcerated individuals and their families learn to identify family dynamics, substance abuse issues, and mental health concerns that contribute to the presenting problem(s); identify the causes of conflict in their families; learn more effective problem-solving and interpersonal communication skills (Rojas \& Peters, 2016); practice reducing negative automatic thoughts and schemas, hostile feelings, and aggressive behaviors; learn to improve family functioning by regulating their emotions, beliefs, and behavioral exchanges; and learn and practice skills that help them avoid destructive patterns of behavior. When offenders are involved in family interventions, they are also more likely to participate in other prison programs (Showalter \& Williams Jones, 1980) and as they learn how to maintain healthy relationships, family-driven crises are reduced (Rieger, 1973).

\section{Improved Parenting Skills}

Family therapy helps parents by building parental confidence and teaching more effective parenting skills including how to reward positive behaviors, having realistic expectations of their children, and learning how to replace blame with accountability (Kolko et al., 2014). Other benefits include decreases in children's acting out in school and at home and a reduced likelihood that the children of incarcerated parents will also be incarcerated in the future. According to Petersilia (2003), the rates of future incarceration for children of incarcerated parents are 5 times those of children whose parents have not served time in prison. 


\section{Family Cohesion}

Furthermore, the literature points to family therapy improving family cohesion and support (Datchi et al., 2016), improving the family's understanding of individual psychopathology as well as family dysfunction, increasing awareness of the contribution of family dynamics in each family member's behavior, improving abilities to cope with stressors, and enhancing communication and trust within the family (Swank \& Gagnon, 2016).

\section{Barriers to Program Implementation}

Some of the barriers to implementing prison programs include resources and funding, retribution and "hug-a-thug" attitudes from other employees and prison administrators, staffing issues and complacency, a scarcity of evaluation studies, and, specifically for family therapy, the long traveling distances to correctional facilities for family members.

\section{Resources and Funding}

Particularly in state-run facilities, correctional budgets are often a small percentage of the entire state's budget. Within that limited budget are monies for custody staff primarily and the minimal amount of noncustody staff required to run other departments such as medical, mental health, and religious services. Therefore, correctional mental health staff tends to have an inadequate amount of time and resources to focus on ancillary services.

\section{Retribution}

Another barrier is the negative attitudes of correctional staff toward inmates. The notion of retribution still prevails in criminal justice systems. That is, offenders are viewed as needing to be punished for their crimes and part of that punishment is to isolate them from their family and friends. Clearly, that contradicts the goals of family therapy. Those who provide services that benefit offenders are seen as "hug-a-thugs" or having favorable views of inmates.

\section{Staffing and Complacency}

In addition to a lack of adequate staffing to effectively implement therapeutic interventions, complacency in government agencies negatively impacts the promotion of novel ideas. Unlike in the private sector, the pay scales for government workers are fixed with step increases occurring annually regardless of performance. Hence, there is little incentive to take on additional projects or to make changes to the comfort of daily routines.

\section{Insufficient Research}

In terms of receiving funding for family-focused interventions in correctional settings, there simply aren't the necessary evaluation studies that justify the need to allocate funds in this area. Most of the research has focused on juvenile justice family services, which has resulted in a number of EBPs for youthful offenders. There is a large gap in the literature where adult family-focused therapeutic interventions are concerned. For all these reasons "family intervention programs .... are rarely implemented in correctional facilities" (Barretti \& Beitin, 2010, p. 41). 


\section{Practical Problems for Families}

Lastly, prisons are rarely built in convenient in-town locations, which creates long driving distances for incarcerated families to participate in weekly family sessions at these institutions. In order for offenders and their families to receive the benefits of family therapy, a commitment to meet regularly is an essential component. That translates into the expectation of resources (mode of transportation, the cost of gas, etc.) that the families often do not have. It is incumbent on those looking to improve correctional programming to find creative solutions to these problems.

\section{Solutions}

\section{Grants}

Federal and state grants are available to address the lack of fiscal resources needed to implement prison programs. For instance, the Second Chance Act of 2007 authorizes the use of federal dollars that support prison programs such as substance abuse treatment and family interventions for inmates nearing the end of their sentences. An important element in securing grant money for reentry services is the implementation of EBPs that align with the RNR principle. In other words, correctional systems are more likely to be funded if the interventions relied on have been empirically proven to reduce recidivism rates.

\section{Policy Makers and Institutional Staff}

Another important aspect of positively impacting policy makers and institutional staff to obtain buy-in for prison programs is to provide regular in-service training to all staff on the importance of reentry services. However, the training should focus on the impact that reentry services have on creating safer communities, which is important to the mission of corrections, rather than simply improving the lives of offenders. This shift in focus may help reduce some of the skepticism that is prevalent in criminal justice agencies.

\section{Teletherapy}

One of the benefits of living in a technology-driven society is the ability to provide counseling to individuals and families without having to be in the same room. A number of computer applications support video calls, such as FaceTime, Skype, Facebook Messenger, and Google Duo. These applications either come with smart phones, tablets, and other electronic devices or can be downloaded at no cost to the user. While most therapists prefer to see their clients face-to-face, video calling can be an indispensable solution for families who are unable to drive the long distances to the institutions.

\section{Internships and Practicums}

A solution to the limited number of staff available to conduct prison programs is to create internships and practicum opportunities for students from local universities. If, as is often the case, hiring more staff is budgetarily impossible, graduate students are a solution (Barretti \& Beitin, 2010). For instance, marriage and family therapy (MFT) graduate programs require a certain number of individual, couple, and family therapy contact hours in order to sit for licensure. The number of hours varies by state, but they are obtained at internship and practicum sites. By hiring one licensed supervisor, mental health departments could create family therapy programs with three or more unpaid MFT graduate students who would provide the therapy to inmates and their families. Furthermore, after obtaining their contact hours, completing their degrees, and having gained 
correctional experience, these students could apply for correctional mental health positions as they become available in the institutions. This would also improve the quality of the candidates recruited in correctional settings.

\section{Conclusions}

Family therapy in corrections addresses family conflict, a criminogenic need or risk that is associated with recidivism. Through actuarial risk assessments, such as the Ohio Risk Assessment System or the California Static Risk Assessment, inmates may be identified as being at high risk in the area of family and social support and targeted for services.

While there are several challenges that correctional administrators face in implementing psychotherapeutic interventions in prison, there are also viable solutions that can be put into place with little or no extra cost to mental health budgets. The most important one is formalizing internship programs or practicum placements within correctional mental health systems. This way MFT students or similarly trained graduate students would earn contact hours for licensure while providing family therapy in correctional institutions. Moreover, with family programs in place, evaluation studies would be needed to ensure adherence to EBPs and to supplement the scarcity of research on family therapy in adult correctional systems.

\section{Author's Note}

This article was presented at the National Conference on Correctional Health Care on October 22, 2018, in Las Vegas, NV.

\section{Declaration of Conflicting Interests}

The author declared no potential conflicts of interest with respect to the research, authorship, and/or publication of this article.

\section{Funding}

The author received no financial support for the research, authorship, and/or publication of this article.

\section{References}

Andrews, D. A., \& Bonta, J. (2010). The psychology of criminal conduct (5th ed.). LexisNexis Matthew Bender. Andrews, D. A., Bonta, J., \& Wormith, J. S. (2006). The recent past and near future of risk and/or need assessment. Crime \& Delinquency, 52(1), 7-27. https://doi.org/10.1177/0011128705281756

Barretti, L. M., \& Beitin, B. K. (2010). Creating internships in marriage and family therapy: A collaboration between a training program and an offender reentry facility. Contemporary Family Therapy, 32(1), 39-51. https://doi.org/10.1007/s10591-009-9109-3

Carr, A. (2014). The evidence base for couple therapy, family therapy and systemic interventions for adultfocused problems. Journal of Family Therapy, 36(2), 158-194. https://doi.org/10.1111/1467-6427.12033

Celinska, K. (2015). Effectiveness of functional family therapy for mandated versus non-mandated youth. Juvenile and Family Court Journal, 66(4), 17-27. https://doi.org/10.1111/jfcj.12049

Datchi, C. C., Barretti, L. M., \& Thompson, C. M. (2016). Family services in adult detention centers: Systemic principles for prisoner reentry. Couple and Family Psychology: Research and Practice, 5(2), 89-104. https://doi.org/10.1037/cfp0000057

Datchi, C. C., \& Sexton, T. L. (2013). Can family therapy have an effect on adult criminal conduct? Initial evaluation of functional family therapy. Couple and Family Psychology: Research and Practice, 2(4), 278-293. https://doi.org/10.1037/a0034166

Dowden, C., \& Andrews, D. A. (2000). Effective correctional treatment and violent reoffending: A metaanalysis. Canadian Journal of Criminology, 42(4), 449-467. 
Gendreau, P., French, S. A., \& Gionet, A. (2004). What works (what doesn't work): The principles of effective correctional treatment. Journal of Community Corrections, 13(3), 4-10.

Henggeler, S. W., \& Schaeffer, C. M. (2016). Multisystemic therapy ${ }^{\circledR}$ : Clinical overview, outcomes, and implementation research. Family Process, 55(3), 514-528. https://doi.org/10.1111/famp.12232

Hofmann, S. G., Asnaani, A., Vonk, I. J. J., Sawyer, A. T., \& Fang, A. (2012). The efficacy of cognitive behavioral therapy: A review of meta-analyses. Cognitive Therapy and Research, 36(5), 427-440. https:// doi.org/10.1007/s10608-012-9476-1

Kolko, D. J., Campo, J., Kilbourne, A. M., Hart, J., Sakolsky, D., \& Wisniewski, S. (2014). Collaborative care outcomes for pediatric behavioral health problems: A cluster randomized trial. Pediatrics, 133(4), e981e992. https://doi.org/10.1542/peds.2013-2516

Lipsey, M. W., Landenberger, N. A., \& Wilson, S. J. (2007). Effects of cognitive-behavioral programs for criminal offenders. Campbell Systematic Reviews, 6. https://doi.org/10.4073/csr.2007.6

Minuchin, S. (1974). Families and family therapy. Harvard University Press.

Petersilia, J. (2003). When prisoners come home: Parole and prisoner reentry. Oxford University Press.

Rieger, W. (1973). A proposal for a trial of family therapy and conjugal visits in prison. American Journal of Orthopsychiatry, 43(1), 117-122. https://doi.org/10.1111/j.1939-0025.1973.tb00791.x

Rojas, E. C., \& Peters, R. H. (2016). Evidence-based practices for co-occurring disorders in offenders. Addiction Research \& Theory, 24(3), 223-235. https://doi.org/10.3109/16066359.2015.1102896

Showalter, D., \& Williams Jones, C. (1980). Marital and family counseling in prisons. Social Work, 25(3), 224-228. https://doi.org/10.1093/sw/25.3.224

Simons, I., Mulder, E., Breuk, R., Mos, K., Rigter, H., van Domburgh, L., \& Vermeiren, R. (2017). A program of family-centered care for adolescents in short-term stay groups of juvenile justice institutions. Child and Adolescent Psychiatry and Mental Health, 11, 61. https://doi.org/10.1186/s13034-017-0203-2

Substance Abuse and Mental Health Services Administration. (2014). SAMHSA's concept of trauma and guidance for a trauma-informed approach (SMA 14-4884). Author. https://store.samhsa.gov/system/files/ sma14-4884.pdf

Swank, J. M., \& Gagnon, J. C. (2016). Mental health services in juvenile correctional facilities: A national survey of clinical staff. Journal of Child and Family Studies, 25(9), 2862-2872. https://doi.org/10.1007/ s10826-016-0436-3

Szapocznik, J., \& Williams, R. A. (2000). Brief strategic family therapy: Twenty-five years of interplay among theory, research and practice in adolescent behavior problems and drug abuse. Clinical Child and Family Psychology Review, 3(2), 117-134. https://doi.org/10.1023/A:1009512719808

Underwood, L. A., Phillips, A., von Dresner, K., \& Knight, P. D. (2006). Critical factors in mental health programming for juveniles in corrections facilities. International Journal of Behavioral Consultation and Therapy, 2(1), 107-140. http://dx.doi.org/10.1037/h0100771

Vera Institute of Justice Family Justice Program. (2011). Why ask about family? A guide for corrections. Author. https://www.vera.org/downloads/Publications/why-ask-about-family-a-guide-for-corrections/ legacy_downloads/Why-ask-about-family-Final.pdf 